\title{
STUDY ON ENDOMETRIAL THICKNESS BY TRANSVAGINAL ULTRASONOGRAPHY AND ITS HISTOLOGICAL CORRELATION IN PATIENTS WITH POSTMENOPAUSAL BLEEDING
}

\author{
Arpana Kumari ${ }^{1}$, Chitra Sinha ${ }^{2}$, Chander Kiran ${ }^{3}$, Nibha Mohan $^{4}$, Supriya Kumari ${ }^{5}$, Punita Kumari 6 \\ ${ }^{1}$ Postgraduate Student, Department of Obstetrics and Gynaecology, Patna Medical College \& Hospital, Patna, Bihar. \\ ${ }^{2}$ Associate Professor, Department of Obstetrics and Gynaecology, Patna Medical College \& Hospital, Patna, Bihar. \\ ${ }^{3}$ Head, Department of Obstetrics and Gynaecology, Patna Medical College \& Hospital, Patna, Bihar. \\ ${ }^{4}$ Senior Resident, Department of Obstetrics and Gynaecology, Patna Medical College \& Hospital, Patna, Bihar. \\ 5Postgraduate Student, Department of Obstetrics and Gynaecology, Patna Medical College \& Hospital, Patna, Bihar. \\ ${ }^{6}$ Postgraduate Student, Department of Obstetrics and Gynaecology, Patna Medical College \& Hospital, Patna, Bihar.
}

\begin{tabular}{l}
\hline ABSTRACT \\
BACKGROUND \\
Objective- To diagnose the causes of post-menopausal bleeding and to correlate endometrial thickness by transvaginal sonography \\
and histopathology by dilatation and curettage.
\end{tabular}

\section{MATERIALS AND METHODS}

This study was carried out in the Department of Obstetrics and Gynaecology, PMCH, Patna, Bihar, over a period of 2 years, from October 2014 to September 2016. A total of 100 postmenopausal women complaining of vaginal bleeding were included in the study. These women were subjected to Transvaginal ultrasonography (TVS) and Dilatation \& Curettage (D\&C) to obtain endometrial tissues for histopathological examination.

\section{RESULTS}

Mean endometrial thickness was $8.72 \pm 6.77 \mathrm{~mm}$. Majority of patients (48\%) had endometrial thickness $\leq 4 \mathrm{~mm}$ followed by $19 \%$ who had 11-15 mm, 14\% had 5-10 mm, 10\% had >20 mm and 9\% had 16-20 mm endometrial thickness. Histopathologically, 48\% had atrophy, $16 \%$ had endometrial hyperplasia, $12 \%$ each had proliferative and endometrial carcinoma, $9 \%$ had endometrial polyp while $3 \%$ had endometritis.

\section{CONCLUSION}

A conservative approach may be offered to women with post-menopausal bleeding showing endometrial thickness of $<4$ mm, thereby avoiding the need for curettage in large number of women.

\section{KEYWORDS}

Postmenopausal Bleeding, Transvaginal Sonography, Endometrial Thickness, Histopathology, Dilatation and Curettage.

HOW TO CITE THIS ARTICLE: Kumari A, Sinha C, Kiran C, et al. Study on endometrial thickness by transvaginal ultrasonography and its histological correlation in patients with postmenopausal bleeding. J. Evolution Med. Dent. Sci. 2017;6(41):3201-3204, DOI: $10.14260 /$ Jemds/2017/693

\begin{tabular}{|c|c|}
\hline $\begin{array}{l}\text { BACKGROUND } \\
\text { Postmenopausal bleeding is a common gynaecological } \\
\text { presentation and represents } 5 \% \text { of all gynaecologic } \\
\text { outpatient attendances. }{ }^{1} \text { In postmenopausal women, any } \\
\text { vaginal bleeding is considered abnormal and requires } \\
\text { evaluation. }{ }^{2} \text { Menopause occurs when a woman's ovaries stop } \\
\text { producing hormones, resulting in the end of her menstrual } \\
\text { periods. It is defined as having no menstrual period for } 12\end{array}$ & $\begin{array}{l}\text { However, high oestrogen produced endogenously in some } \\
\text { women may keep the endometrium proliferative and even } \\
\text { hyperplastic. Most women globally experience natural } \\
\text { menopause between the ages of } 40 \text { and } 58 \text {, with the average } \\
\text { age of onset around } 51 \text { years of age. The average age of } \\
\text { menopause in India is } 47.5 \text { years. Even without amenorrhea } \\
\text { or irregularity, menstruation continuing after the age of } 55 \\
\text { years should be investigated. }\end{array}$ \\
\hline
\end{tabular}
months. ${ }^{3}$ The changes in the genital tract at the menopausal transition are primarily due to changes in circulating sex hormones and partly due to ageing process. The corpus: cervix ratio returns to $1: 2$ as in childhood. The stroma of endometrium becomes fibrous and the endometrium becomes atrophic, though cystic glands may persist for years.

Financial or Other, Competing Interest: None.

Submission 17-04-2017, Peer Review 11-05-2017,

Acceptance 17-05-2017, Published 22-05-2017.

Corresponding Author:

Dr. Arpana Kumari,

C/o Raj Mohan Jha, $3^{\text {rd }}$ Street,

Sipahi Tola, Chunapur Road,

Purnea, Bihar.

E-mail: arpanamishra03@gmail.com

DOI: $10.14260 /$ jemds $/ 2017 / 693$

\section{Important causes of Postmenopausal bleeding are}

- Vaginal atrophy -the most common cause of PMB. ${ }^{4}$

- Use of HRT

- Endometrial hyperplasia; simple, complex, and atypical.

- Endometrial cancer.

- Endometrial polyps or cervical polyps.

- Cervical cancer.

- Ovarian cancer, especially oestrogen-secreting (theca cell) ovarian tumours.

- Vaginal cancer (very uncommon).

- Vulval cancer may bleed, but the lesion should be obvious.

- Uterine sarcoma (rare).

- Non-gynaecological causes including trauma or a bleeding disorder. 
The risk of endometrial cancer increases with age and presence of risk factors. Transvaginal ultrasonography is an important screening tool for evaluation of post-menopausal bleeding. 5 Transvaginal ultrasonography is superior to Transabdominal ultrasonography as it has permitted the use of higher frequency ultrasound at greater proximity to the uterus and the endometrial - myometrium interface can be seen clearly.

Measurement of endometrial thickness using Transvaginal ultrasonography is helpful in diagnosis of endometrial pathology, including endometrial cancer and in assessment of myometrium invasion.

\section{MATERIALS AND METHODS}

This observational study was carried out in Department of Obstetrics and Gynaecology at Patna Medical College and Hospital, Patna between October 2014 and September 2016. 100 postmenopausal women complaining of vaginal bleeding were included in the study.

\section{Inclusion Criteria}

The postmenopausal women with bleeding per vaginum were included in the study.

\section{Exclusion Criteria}

The postmenopausal women who were:

- On hormone replacement therapy.

- Taking tamoxifen for breast cancer.

- Having local causes of bleeding (Vaginal, vulval or cervical causes).

Transvaginal ultrasonography was done using $8 \mathrm{MHz}$ an endovaginal probe fitted in GE LOGIQ P3 model ultrasonography machine. The endometrial thickness was reported as double-thickness measurement in midsagittal view.

Dilatation and curettage to obtain tissue for histopathological examination was done in each case. The curetted material was placed in $10 \%$ formalin solution, labelled properly and sent for histopathological examination.

\section{Statistical Analysis}

Descriptive data were presented as mean \pm SD and range values. Multiple group comparisons were done by Chi square test. For all the tests, the probability value (p-value) of less than 0.05 was considered statistically significant.

\section{RESULTS}

100 women with postmenopausal bleeding were investigated and were subjected to transvaginal sonography to measure endometrial thickness and endometrial biopsy was performed. The correlation between endometrial thickness and histopathology of endometrial tissue was done.

\begin{tabular}{|c|c|c|}
\hline Sl. No. & Characteristics & Women(n=100) \\
\hline 1. & Mean age(years) & $53.95 \pm 6.79$ \\
\hline 2. & $\begin{array}{c}\text { Mean duration of } \\
\text { menopause(years) }\end{array}$ & $6.4 \pm 4.59$ \\
\hline 3. & Mean parity & $4.46 \pm 1.93$ \\
\hline 4. & Hypertension & $20 \%$ \\
\hline 5. & Obesity & $16 \%$ \\
\hline 6. & Diabetes mellitus & $12 \%$ \\
\hline \multicolumn{3}{|c|}{ Table 1. Characteristics of Study Women } \\
\hline
\end{tabular}

Maximum no. of cases was in the age group of 45-50 years i.e. 48 cases $(48 \%)$. Mean age was $53.95 \pm 6.79$ years and range was 45 to 75 years. Maximum no. of cases had parity above 4 i.e. $\geq \mathrm{P} 5$ (59\%). Mean parity was $4.46 \pm 1.93$ and median parity was 5 with range of 0 to 8 . In this study, maximum no. of cases had attained menopause 1-5 years back. The mean duration of menopause was $6.4 \pm 4.59$ years and the range of distribution was 1 to 20 years.

The mean BMI was $25.08 \pm 4.336 \mathrm{Kg} / \mathrm{m}^{2}$ and $16 \%$ patients were obese i.e. BMI $\geq 30 \mathrm{Kg} / \mathrm{m}^{2}$. The mean Systolic $\mathrm{BP}$ was $124 \pm 16.53 \mathrm{mmHg}$ and mean Diastolic BP was $78.2 \pm$ $11 \mathrm{mmHg}$. Majority of cases had BP less than 120/80 mmHg (53\%), while $20 \%$ of cases were hypertensive. Diabetes mellitus was present in $12 \%$ patients, while $88 \%$ were nondiabetic.

\begin{tabular}{|c|c|c|c|c|c|c|c|}
\hline ET (mm) & AE & PE & EH & EP & EC & Endometritis & Total \\
\hline$\leq 4$ & 48 & 0 & 0 & 0 & 0 & 0 & 48 \\
\hline $5-10$ & 0 & 9 & 1 & 2222 & 0 & 2 & 14 \\
\hline $11-15$ & 0 & 3 & 10 & 4 & 1 & 1 & 19 \\
\hline $16-20$ & 0 & 0 & 4 & 3 & 2 & 0 & 9 \\
\hline$>20$ & 0 & 0 & 1 & 0 & 9 & 0 & 10 \\
\hline Total & $\mathbf{4 8}$ & $\mathbf{1 2}$ & $\mathbf{1 6}$ & $\mathbf{9}$ & $\mathbf{1 2}$ & $\mathbf{3}$ & $\mathbf{1 0 0}$ \\
\hline Mean ET & $\mathbf{3 . 1}$ & $\mathbf{8 . 6}$ & $\mathbf{1 4 . 1}$ & $\mathbf{1 2 . 9}$ & $\mathbf{2 1 . 2}$ & $\mathbf{8 . 3}$ & $\mathbf{8 . 7 2}$ \\
\hline
\end{tabular}

Table 2. Distribution of Cases According to Endometrial Thickness in Relation to Histopathology

ET-Endometrial Thickness, AE-Atrophic Endometrium, PE-Proliferative Endometrium, EH-Endometrial Hyperplasia, EP-Endometrial Polyp, EC-Endometrial Carcinoma

Mean Endometrial thickness was $8.72 \pm 6.77 \mathrm{~mm}$. Majority of patients (48\%) had endometrial thickness $\leq 4 \mathrm{~mm}$ followed by $19 \%$ who had $11-15 \mathrm{~mm}, 14 \%$ had $5-10 \mathrm{~mm}$, $10 \%$ had $>20 \mathrm{~mm}$ and $9 \%$ had $16-20 \mathrm{~mm}$ endometrial thickness. Histopathologically, 48\% had atrophy, 16\% had endometrial hyperplasia, $12 \%$ each had proliferative and endometrial carcinoma, 9\% had endometrial polyp while 3\% had endometritis.

All 48 cases with endometrial thickness $\leq 4 \mathrm{~mm}$ had atrophic endometrium. When ET was $<11 \mathrm{~mm}$, no endometrial carcinoma was seen, whereas when ET was 16$20 \mathrm{~mm}, 18 \%$ ( 2 out of 9) had endometrial carcinoma. There were 10 cases having endometrial thickness greater than 20 $\mathrm{mm}$ and 9 out of these 10 cases (90\%) had endometrial carcinoma on histopathology.

Mean ET was $3.1 \mathrm{~mm}$ for atrophic changes while it was $21.2 \mathrm{~mm}$ in case of carcinoma.

\section{DISCUSSION}

PMB is the presenting complaint in approximately $90 \%$ of women with endometrial carcinoma. ${ }^{6}$ The main aim of investigating these women is to rule out endometrial cancer and its precursor lesion and endometrial hyperplasia. The probability of endometrial cancer in women presenting with postmenopausal bleeding is approximately $10 \%$.

In our study, the range of distribution of age was 45 to 75 years. The mean age \pm SD was $53.95 \pm 6.79$ years. This correlates with study done by Indu Kaul et al $(2012)^{7}$ where they found mean age of patients as $54.0 \pm 6.64$ years and range was 41 to 70 years. I Bano et al $(2013)^{8}$ observed mean 
age as 52 years, and age range as $46-76$ years. M Viswanathan et al $(2014)^{9}$ observed mean age as $55.5 \pm 6.4$ years.

In our study, mean parity \pm SD was $4.46 \pm 1.93$. Median parity was 5 (range 0 to 8 ). This correlates with study done by I. Bano et al $(2013)^{8}$, who also found median parity as 5 , and range 0 to 10 .

The mean duration of menopause in our study was $6.4 \pm$ 4.59 years and the range of distribution was 1 to 20 years, which was similar to the findings of M Viswanathan et al (2014) ${ }^{9}$ who observed mean duration of menopause to be $4 \pm$ 6.5 years and range to be $1-40$ years.

In our study, 16 out of $100(16 \%)$ patients had obesity i.e. BMI $\geq 30 \mathrm{Kg} / \mathrm{m}^{2}$, which was not in accordance with the results of the study by Nirupama $V$ et al (2015) ${ }^{10}$ where $45 \%$ of their cases were obese, whereas M Vishwanathan et al $(2014)^{9}$ found obesity in $6.6 \%$ and overweight in $63.3 \%$ which was not in accordance with the findings of present study. Obesity, diabetes and hypertension are important risk factors for endometrial carcinoma. ${ }^{11}$

In present study, mean Systolic BP was $124 \pm 16.53$ $\mathrm{mmHg}$ and mean Diastolic BP was $78.2 \pm 11 \mathrm{mmHg}$. Majority of cases had BP less than 120/80 mmHg (53\%) while $20 \%$ of cases were with $\mathrm{BP}>140 / 90 \mathrm{mmHg}$ i.e. hypertensive, which correlates with results of study by Indu Kaul et al $(2012)^{7}$ who also found hypertension in $20 \%$ cases. Diabetes mellitus was present in $12 \%$ cases, which correlates with observation of Nirupama V et al (2015) ${ }^{10}$ who found $13 \%$ diabetic patients in their study group.

An atrophic endometrium generally not exceeds $3 \mathrm{~mm}$ ET. It was found that the endometrium of less than $4 \mathrm{~mm}$ thickness as seen by ultrasonography was well correlated with endometrial characteristics of decreased oestrogen stimulation. Among patients of postmenopausal bleeding, $48 \%$ had atrophic endometrium, while Indu Kaul et al $(2012)^{7}$ found $50 \%$ atrophic endometrium in their study. $12 \%$ endometrial carcinoma cases were observed in the our study, while G Conoscenti et al (1995) ${ }^{12}$ found $13.4 \%$, Indu Kaul et al $(2012)^{7}$ found $10 \%$, and Myrvete Pacaradaet al (2009) $^{13}$ observed only $5 \%$ cases of endometrial carcinoma in their study.

In our study, mean ET on TVS for atrophy was $3.1 \mathrm{~mm}$, while Indu Kaul et al $(2012)^{7}$ observed $4.00 \pm 1.12 \mathrm{~mm}$ and Karlsson B et al (1996) ${ }^{14}$ found $3.9 \pm 2.5 \mathrm{~mm}$. Similarly, for endometrial carcinoma mean ET was $21.2 \mathrm{~mm}$, while Indu Kaul et al $(2012)^{7}$ observed $25.00 \pm 5.09 \mathrm{~mm}$ and Karlsson B et al $(1996)^{14}$ found $21.1 \pm 11.8 \mathrm{~mm}$.

Among the patients with endometrial carcinoma, majority (11 out of $12,91.7 \%$ ) had endometrial thickness $>16 \mathrm{~mm}$. Patients of postmenopausal bleeding with endometrial thickness $>20 \mathrm{~mm}$, majority (9 out of $10,90 \%$ ) had endometrial carcinoma ( $P$ value - 0.001). Indu Kaul et al $(2012)^{7}$ showed that $75 \%$ cases with endometrial thickness more than $20 \mathrm{~mm}$ were diagnosed as endometrial carcinoma. Thus, incidence of endometrial carcinoma was high when endometrium was $>20 \mathrm{~mm}$ thick. Hence, endometrial thickness measurement by transvaginal ultrasonography is very important for further evaluation of postmenopausal bleeding patients. Endometrial thickness $<4 \mathrm{~mm}$ does not require further evaluation by invasive procedure while thickness more $>11 \mathrm{~mm}$ requires definitive diagnostic invasive procedure.

\section{CONCLUSION}

In all cases of postmenopausal bleeding, evaluation should be done to rule out malignancy. It requires careful evaluation and timely assessment for making correct diagnosis. As initial evaluation, transvaginal sonography is used and according to endometrial thickness histopathological correlation is also done. Transvaginal sonography is an effective procedure to exclude endometrial and intrauterine abnormalities. It is relatively easy, cheap, non-invasive and without any side effects and does not require anaesthesia.

Endometrial thickness by transvaginal ultrasonography can be used as a reliable method for excluding malignancy. No case of endometrial cancer was found when endometrium was less than $4 \mathrm{~mm}$ thick.

\section{REFERENCES}

[1] Moodley M, Roberts C. Clinical pathway for the evaluation of postmenopausal bleeding with an emphasis on endometrial cancer detection. J Obstet Gynecol 2004;24(7):736-41.

[2] Vilos GA, Lefebvre G, Graves GR. Guidelines for the management of abnormal uterine bleeding. J Obstet Gynaecol Can 2001;23(8):704-9.

[3] American College of Obstetricians and Gynecologists. ACOG practice bulletin, clinical management guidelines for obstetrician-gynecologists, number 65 , August 2005: management of endometrial cancer. Obstet Gynecol 2005;106(2):413-25.

[4] Munot S, Lane G. Modern management of postmenopausal bleeding. Trends in Urology and Men's Health 2008;13(5):20-4.

[5] Dubinsky TJ, Parvey HR, Maklad N. The role of transvaginal sonography and endometrial biopsy in the evaluation of peri-and postmenopausal bleeding. AJR Am J Roentgenol 1997;169(1):145-9.

[6] Lurain JR. Uterine cancer. In: Berek JS, Adashi EY, Hillard PA. (eds.) Novak's Gynecology. $12^{\text {th }}$ edn. Baltimore: Williams \& Wilkins, 1996:1057-110.

[7] Kaul I, Kalsi M, Anand AK, et al. Transvaginal sonography versus histopathology in postmenopausal bleeding: a prospective study. JK Science 2012;14(3):129.

[8] Bano I, Mittal G, Khalid M, et al. A study of endometrial pathology by transvaginal Color Doppler ultrasonography and its correlation with histopathology in post-menopausal women. Indian Medical Gazette 2013;134-9.

[9] Viswanathan M, Daniel S, Shailaja M, et al. Socio demographic profile of patients with postmenopausal bleeding attending outpatient unit of a tertiary care centre. Sch J App Med Sci 2014;2(2C):681-4.

[10] Nirupama V, Suneetha Y, Devi PK. Postmenopausal bleeding: an analytic study of 100 cases. International Journal of Science and Research 2015;4(6):2588-90.

[11] Munro MG. Investigation of women with postmenopausal uterine bleeding: clinical practice recommendations. Perm J 2014;18(1):55-70. 
[12] Conoscenti G, Meir YJ, Fischer-Tamaro L, et al. Endometrial assessment by transvaginal sonography and histological findings after D \& C in women with postmenopausal bleeding. Ultrasound Obstet Gynecol 1995;6(2):108-15.

[13] Paçarada M, Lulaj S, Kongjeli N, et al. Correlation of postmenopausal endometrial changes determined by transvaginal sonography and histopathological analysis. J Turkish-German Gynecol Assoc 2009;10:35-8.
[14] Karlsson B, Granberg S, Wickland M, et al. Transvaginal ultrasonography of the endometrium in women with postmenopausal bleeding-a Nordic multicentre study. Am J Obstet Gynecol 1995;172(5):1488-94. 